REVIEW ARTICLE

\title{
Efeitos da radiação UV-C em alface e maçã minimamente processadas: uma revisão
}

\author{
Effects of UV-C radiation on minimally processed lettuce and \\ apple: a review
}

\author{
Clóvis Antônio Balbinot Filho ${ }^{1}$ (D), Caroline Dellinghausen Borges ${ }^{1 *}$ \\ ${ }^{1}$ Universidade Federal de Pelotas (UFPel), Centro de Ciências Químicas, Farmacêuticas e de Alimentos, \\ Pelotas/RS - Brasil
}

${ }^{*}$ Corresponding Author: Caroline Dellinghausen Borges, Universidade Federal de Pelotas (UFPel), Centro de Ciências Químicas, Farmacêuticas e de Alimentos, Campus Capão do Leão, Prédio 4, CEP: 96010-900,

Pelotas/RS - Brasil, e-mail: caroldellin@bol.com.br

Cite as: Balbinot Filho, C. A., \& Borges, C. D. (2020). Effects of UV-C radiation on minimally processed lettuce and apple: a review. Brazilian Journal of Food Technology, 23, e2018321. https://doi.org/10.1590/1981-6723.32118

\begin{abstract}
Resumo
A alta procura por alimentos nutritivos e de fácil consumo tem impulsionado o mercado de frutas e hortaliças minimamente processadas (MP). No entanto, estes alimentos têm uma curta vida de prateleira, são marcados pela rápida deterioração. A radiação ultravioleta-C (UV-C) é uma técnica não térmica, limpa e de baixo custo que pode servir como alternativa aos sanitizantes comuns. Porém, a sua baixa penetração em alimentos tem limitado sua aplicação neste ramo da indústria. Objetivou-se revisar o efeito germicida da radiação UV-C em alface e maçã minimamente processados e os possíveis danos às características físicas e sensoriais, além de realizar uma avaliação dos fatores envolvidos nesta técnica. Uma redução de 1 a $2 \log$ UFC/g da microflora natural destes vegetais é facilmente atingida com doses moderadas, para diversos grupos de microrganismos deteriorantes. Uma maior redução nos níveis de patogênicos inoculados, acima de $4 \log$ UFC/g, foi verificada quando doses maiores foram utilizadas. Para a alface MP, a superfície irregular é considerada um limitante, por reduzir o contato entre a radiação e os microrganismos. Essa limitação pode ser superada alterando parâmetros do processo, como distância da fonte emissora e exposição de ambos os lados do vegetal. A cor das folhas foi melhor preservada com emprego de radiação UV-C em doses moderadas. Na maçã MP, alterações indesejáveis, como a intensa perda de massa e o escurecimento pronunciado, estão associadas a um severo dano celular em doses mais elevadas. Tais efeitos puderam ser evitados expondo a fruta por um menor tempo. Em geral, verificou-se boa aceitabilidade de alface e maçã MP tratadas com radiação UV-C. O tipo de fruta ou hortaliça utilizado e a sua topografia exercem grande influência na eficiência da técnica. Não foi possível sugerir uma dosagem adequada para a alface ou a maçã MP, visto que os poucos estudos disponíveis diferem quanto à variedade de alface ou maçã estudada, na forma como os tratamentos foram conduzidos e na dose exposta.
\end{abstract}

Palavras-chave: Processamento mínimo; Dose; Microrganismos; Efeito germicida; Cor; Vida útil.

\begin{abstract}
The increasing demand for nutritive, ready-to-eat foods has prompted the minimally processed (MP) fruits and vegetables market. However, these foods have short shelf-live, marked by their rapid deterioration. Ultraviolet-C (UV-C) radiation is a clean, low-cost and non-thermal technique that can be an alternative to commonly used
\end{abstract}


sanitizers. However, this conservation method has a limited application in this branch of industry due to its low penetration in foods. The objective of this review was to evaluate the germicidal effect of UV-C radiation on minimally processed lettuce and apple, the possible damage to physical and sensorial properties, as well as the factors involved in this technique. A log reduction from 1 to $2 \log$ CFU/g of the natural microflora of these vegetables can be easily achieved at moderate doses, for diverse groups of spoilage microorganisms. A higher reduction level above $4 \log$ CFU/g of inoculated pathogens was accomplished, when higher doses were applied. For MP lettuce, its irregular surface is considered a limiting factor due to contact attenuation between radiation and microorganisms. This limitation can be overcome by changing process parameters, such as distance from the emitting source and exposing both sides of the lettuce. The color of the leaves was better preserved with the use of UV-C radiation at moderate doses. Undesired alterations in MP apple, such as intense weight loss and pronounced browning were associated to severe cell damage at higher doses. By exposing the fruit for a shorter time, these alterations could be prevented. In general, there was good acceptability of MP lettuce and apple treated with UV-C. The vegetable type and its topography had an important influence on the efficiency of the technique. It was not possible to suggest an adequate dosage for each vegetable seeing that there are few availabe studies that differ between each other in terms of the vegetable variety, the way treatments were conducted and the exposed dose.

Keywords: Minimal processing; Dose; Microorganisms; Germicidal effect; Color; Shelf life.

\section{Introdução}

O aumento no consumo de frutas e hortaliças minimamente processadas (MP) representa um mercado em potencial que acompanha a crescente procura dos consumidores por alimentos frescos, prontos para o consumo, nutritivos, seguros, livres de aditivos e que possam ser incluídos em uma dieta saudável (Manzocco et al., 2011a; Montero-Calderón \& Cerdas-Araya, 2011; Rojas-Graü et al., 2011). No entanto, a conveniência e a atratividade desses produtos são afetadas pela rápida deterioração e curta vida de prateleira, devido a alterações que podem ser de ordem física, química, microbiológica e enzimática (Artés et al., 2007).

Visando controlar essas alterações e manter a segurança alimentar sem comprometer a qualidade nutricional de vegetais MP, tratamentos físicos alternativos ao uso de sanitizantes químicos convencionais têm sido extensivamente estudados (Alothman et al., 2009). Nesse contexto, há considerável literatura a respeito do uso de baixas doses de radiação ultravioleta não ionizante de onda curta (UV-C) como um potencial tratamento pós-colheita para a sanitização superficial e a conservação de vegetais inteiros e MP (Maharaj, 2015).

A irradiação com luz UV-C é uma tecnologia não térmica emergente que apresenta vantagens, como a inativação de uma ampla gama de microrganismos patogênicos e deteriorantes, com mínima perda da qualidade nutricional e sensorial dos alimentos (Gayán et al., 2014). Além de ser um processo frio e a seco, é uma técnica simples e rápida, que não deixa resíduos, não possui restrições legais quanto ao seu uso, e requer baixo investimento e pouco espaço para implantação, podendo ainda ser aplicada em combinação com outras técnicas de conservação (Civello et al., 2006; Yaun et al., 2004), visando a efeitos sinérgicos (Fan et al., 2017).

Recentemente, um crescente interesse na aplicação da radiação UV-C em alimentos tem sido verificado, uma vez que a técnica é tradicionalmente utilizada para a desinfecção de água, ar e superfícies (Gayán et al., 2014). No entanto, o seu limitado uso na indústria alimentícia, aplicado à pasteurização de sucos, é, em parte, devido à pouca penetração $(30$ to $500 \mathrm{~nm}$ ) da radiação na superfície dos tecidos (Artés et al., 2007).

O principal objetivo de tratar os vegetais MP com radiação UV-C é a destruição de microrganismos visando ao aumento da vida útil, cujos efeitos podem ser observados imediatamente após o tratamento, pela absorção da radiação por microrganismos da superfície em doses que são nocivas ao DNA, causando alterações em ácidos nucleicos e membranas (Civello et al., 2006). Ainda, um efeito na indução do metabolismo secundário de defesa dos vegetais, com produção de compostos antimicrobianos, como as 
fitoalexinas (Ribeiro et al., 2012), e aumento da capacidade do tecido irradiado de sintetizar fitoquímicos com propriedades antioxidantes (Alothman et al., 2009) tem despertado o interesse dos pesquisadores em aplicar a radiação UV-C como uma ferramenta para fornecer vegetais mais ricos nutricionalmente, especialmente os MP (Cisneros-Zevallos, 2003).

Contudo, a exposição a altas doses de luz UV-C pode danificar e enfraquecer os tecidos, favorecendo a proliferação de possíveis patógenos (Fan et al., 2017). Existe inconsistência a respeito de qual dose de radiação UV-C é necessária para atingir os efeitos desejados sem causar danos irreversíveis aos tecidos vegetais. Como frutas e hortaliças MP são suscetíveis a um novo estresse, deve haver uma criteriosa seleção da dose de radiação UV-C de acordo com cada vegetal e cada nova variedade testada, a fim de manter a sua qualidade (Civello et al., 2006). Diante do exposto, esta revisão teve por objetivo relatar o efeito germicida da radiação UV-C na sanitização de alface e maçã minimamente processadas, bem como seu efeito sobre características físicas e sensoriais desses produtos, e realizar um levantamento dos principais fatores envolvidos nesta técnica.

\section{Aspectos microbiológicos de frutas e hortaliças minimamente processadas}

O processamento mínimo submete frutas e hortaliças a alterações fisiológicas devido à remoção de sua barreira natural de proteção, o que, por sua vez, favorece o desenvolvimento microbiológico. Como consequência, a qualidade e a segurança dos produtos são afetadas (Ragaert et al., 2011). Logo após o corte, há uma elevação na taxa respiratória, marcada pela alta demanda de oxigênio e maior produção de etileno, que tornam as frutas e hortaliças MP mais perecíveis do que os vegetais in natura. A refrigeração é, então, essencial para conservá-las durante o transporte e a comercialização (Artés et al., 2007).

Frutas e hortaliças MP são geralmente embaladas em recipientes plásticos e seladas com filmes poliméricos, em que o confinamento normalmente induz à formação de uma atmosfera modificada (AM), em função da respiração dos tecidos vivos e da alta umidade na embalagem (Nguyen-the \& Carlin, 1994). Fatores intrínsecos (pH do vegetal e disponibilidade de nutrientes) e extrínsecos (temperatura e a composição gasosa da embalagem) determinam quais tipos de microrganismos irão predominar no produto. Aliado a isso, a manipulação ao longo das etapas de processamento aumenta os riscos de contaminação cruzada por patógenos (Ragaert et al., 2011).

Alterações indesejáveis nos atributos de qualidade de vegetais MP são acompanhadas pelo desenvolvimento microbiológico, especialmente da flora mesófila e psicrotrófica (Artés et al., 2007). Segundo Ragaert et al. (2011), as contagens de microrganismos aeróbios totais (MAT) em produtos MP após o processamento oscilam entre 3 e $6 \log \mathrm{UFC} / \mathrm{g}$. Tendo em vista que os mesmos não são submetidos a nenhuma etapa de esterilização, a refrigeração e o emprego de AM acabam sendo os únicos tratamentos que podem atuar no controle microbiológico (Civello et al., 2006). No entanto, a AM passiva que se estabelece no interior da embalagem pode favorecer o crescimento de leveduras e bactérias acidoláticas. Embora não caracterizem perigo à saúde do consumidor, estes microrganismos são limitantes da qualidade de frutas e hortaliças MP, pois comprometem principalmente o aroma devido à geração de odores indesejáveis (Nguyen-the \& Carlin, 1994; Allende et al., 2006; Bachelli, 2016), os quais, portanto, reduzem a aceitação pelo consumidor. Em frutas MP, bolores e leveduras irão se desenvolver mais facilmente por serem mais tolerantes a um menor $\mathrm{pH}$, enquanto que hortaliças com $\mathrm{pH}$ mais próximo a neutralidade irão favorecer o crescimento de bactérias (Ragaert et al., 2011), grupo que detém a maioria das espécies microbianas patogênicas ao homem.

A ocorrência de surtos alimentares associados à presença de patógenos em frutas e hortaliças MP tem despertado a atenção pela possibilidade de esses alimentos serem veículos para infecções alimentares, em que a contaminação pode ocorrer durante a colheita e o processamento, através de humanos e materiais contaminados (Ragaert et al., 2011). Espécies, como Escherichia coli, Aeromonas, Salmonella sp., Costridium botulinum, Listeria monocytogenes e Staphylococcus aureus, são comumente reportadas nesses alimentos (Artés et al., 2007). 
Os vegetais podem estar naturalmente contaminados por patógenos formadores de esporos, tais como Bacillus cereus e os do gênero Clostridium spp. A contaminação por C. botulinum, um patógeno anaeróbio, representa um risco para vegetais embalados sob AM. Já a presença de Staphylococcus aureus é indicativa das condições de higiene dos manipuladores. A refrigeração é fundamental para reduzir o desenvolvimento de patógenos mesófilos, em que temperaturas abaixo de $10{ }^{\circ} \mathrm{C}$ e a própria microflora natural do vegetal podem inibir o crescimento desses microrganismos e, consequentemente, a formação de toxinas (Ragaert et al., 2011). No entanto, bactérias psicrotróficas, como Pseudomonas e Listeria representam o maior risco para a segurança microbiológica de frutas e hortaliças refrigeradas (Cantwell \& Suslow, 2002). A crescente ocorrência de surtos alimentares devido à infecção por L. monocytogenes em vegetais tem chamado a atenção para este patógeno psicrotrófico, que se multiplica sob condições de refrigeração e AM (Ragaert et al., 2011).

Assim, o processamento mínimo não garante a esterilidade ou estabilidade microbiológica do produto, e infecções e intoxicações alimentares podem ocorrer em decorrência do consumo de vegetais contaminados por esses patógenos (Nguyen-the \& Carlin, 1994). Nesse contexto, o uso de radiação UV-C tem se mostrado uma técnica promissora na redução da carga microbiana, juntamente com o aumento da vida útil e a melhora da qualidade geral de diversos produtos hortifrutícolas MP (Civello et al., 2006). No entanto, alguns aspectos pertinentes à aplicação desta técnica necessitam ser elucidados.

\section{A radiação UV-C como agente sanitizante: implicações e limitações}

A irradiação consiste em expor os alimentos à radiação ionizante ou não ionizante com propósito de conservação. A radiação não ionizante não contém energia suficiente para ionizar as moléculas, causando apenas a excitação de elétrons e é representada pela radiação ultravioleta (UV), luz visível, micro-ondas e infravermelho (Alothman et al., 2009; Koutchma \& Orlowska, 2012). A radiação UV abrange a faixa de comprimentos de onda entre 100 e $400 \mathrm{~nm}$, delimitada entre a região dos raios-X e luz visível do espectro eletromagnético, subdividida em três regiões distintas, UV-A, UV-B e UV-C (Cutler \& Zimmerman, 2011).

A radiação UV-C não é encontrada na natureza uma vez que é rapidamente absorvida na atmosfera, trocando energia com o oxigênio e formando o ozônio (Ribeiro et al., 2012). As fontes artificiais de radiação UV comumente utilizadas na inativação de patógenos são lâmpadas que operam com vapor de mercúrio, podendo ser monocromáticas de baixa pressão com pico de emissão de fótons a um comprimento de onda de $254 \mathrm{~nm}$, considerado com maior poder germicida, ou policromáticas de média pressão, que emitem fótons a uma faixa mais ampla de comprimentos de onda abrangendo a região de luz visível (Koutchma \& Orlowska, 2012).

A radiação UV-C entre 250 e $260 \mathrm{~nm}$ é letal para a maioria dos microrganismos (bactérias, vírus, protozoários, fungos, leveduras e algas) e o efeito germicida se dá pela indução da formação de fotoprodutos do DNA bacteriano, comumente dímeros de pirimidina, originados por ligações cruzadas entre bases sensíveis à radiação a $254 \mathrm{~nm}$. Essas alterações comprometem a transcrição e reprodução da célula, levando à morte celular (Gayán et al., 2014; Cutler \& Zimmerman, 2011).

Entretanto, grande parte dos microrganismos detém um potente mecanismo de reparo dos danos causados pela luz UV-C, chamado fotorreativação, que ocorre via absorção da luz visível em comprimentos de onda entre 350 e $500 \mathrm{~nm}$, devido a enzimas liases capazes de reverter o dano causado ao DNA. Esse fenômeno tem sido associado com a exposição à luz após o tratamento com radiação UV-C (Civello et al., 2006; Gayán et al., 2014) e pode ser um fator crítico, considerando frutas e hortaliças MP, que são expostas durante a comercialização sem nenhuma proteção contra a luz.

Diversos fatores podem interferir na sanitização com radiação UV-C e, embora pouco seja conhecido a respeito da sua interação com a matriz alimentícia (Ribeiro et al., 2012), sabe-se que o nível de dano causado ao microrganismo será dependente da quantidade de radiação efetivamente absorvida e da resistência de cada 
espécie (Civello et al., 2006). Para os microrganismos acumularem uma dose letal, é necessária exposição completa da superfície (Koutchma \& Orlowska, 2012). O efeito germicida da luz UV-C pode ser suprimido quando os microrganismos estão internalizados nos tecidos ou aderidos em áreas injuriadas, em que não são afetados pela radiação, pois a luz se torna inacessível às células (Gómez et al., 2015). Nesse sentido, as características superficiais dos vegetais exercem grande influência sobre a eficácia da sanitização com radiação UV-C. A presença de fissuras, cavidades e outras irregularidades, e a própria rugosidade da superfície podem atenuar a energia incidente.

A aplicação comercial da radiação UV-C em alimentos tem sido principalmente limitada pela baixa penetração em sólidos opacos, sendo efetiva apenas para tratamentos superficiais (Manzocco et al., 2011b; Koutchma \& Orlowska, 2012; Birmpa et al., 2013; Fan et al., 2017). Propriedades óticas dos alimentos, como o baixo coeficiente de absorção, causam a atenuação da radiação recebida, que acaba sendo dispersa ou refletida, e, dessa forma, tem seu poder germicida reduzido (Koutchma \& Orlowska, 2012; Gayán et al., 2014). Tendo em vista estes limitantes, na Tabela 1, são elencadas as principais vantagens e desvantagens do emprego de radiação UV-C como um método de conservação em vegetais MP.

Tabela 1. Vantagens e desvantagens do uso de radiação UV-C como método de conservação ${ }^{1}$.

\begin{tabular}{ll}
\hline \multicolumn{1}{c}{ Vantagens } & \multicolumn{1}{c}{ Desvantagens } \\
\hline $\begin{array}{l}\text { - Tratamento não térmico: Nutrientes termossensíveis não } \\
\text { são alterados. }\end{array}$ & $\begin{array}{l}\text { - Tratamento superficial: Devido à baixa penetração, os } \\
\text { tratamentos se limitam a superfícies, filmes e líquidos } \\
\text { claros. }\end{array}$ \\
\hline $\begin{array}{l}\text { - Radiação UV-C é não ionizante, portanto não altera a } \\
\text { natureza química dos componentes dos alimentos e não } \\
\text { deixa resíduos. }\end{array}$ & $\begin{array}{l}\text { - Características superficiais: Irregularidades, poros, fendas } \\
\text { e rugosidade podem proteger os microrganismos da luz } \\
\text { incidente. }\end{array}$ \\
\hline - Os raios UV-C são letais para a maioria dos & $\begin{array}{l}\text { - Interferência de sólidos: Presença de materiais, como } \\
\text { embalagens, entre a luz e o produto interfere na exposição } \\
\text { microrganismos deteriorantes e patogênicos, sendo sua } \\
\text { irradiação comparável a outras técnicas de desinfecção. }\end{array}$ \\
\hline - Técnica simples de aplicar, que requer custos de \\
implementação e manutenção relativamente baixos.
\end{tabular}

A literatura traz que a dose é o fator que mais influencia a eficiência da sanitização com radiação UV-C, que depende da intensidade da radiação emitida pelas lâmpadas UV e do tempo de exposição. Teoricamente, maiores doses e/ou intensidades e tempos de exposição levam a maiores reduções microbianas. No entanto, em alimentos sólidos, esse efeito da dose pode não ocorrer, devido a uma infiltração ineficiente dos raios UV-C na matriz vegetal (Fan et al., 2017). Dessa forma, definir uma dose mínima, mas o suficiente para causar uma redução da carga microbiana em frutas e hortaliças MP sem alterar a qualidade dos produtos ao longo do armazenamento, tem sido alvo de diversos estudos.

\section{Efeitos da radiação UV-C em alface minimamente processada}

\subsection{Aspectos microbiológicos}

A eficiência do uso de radiação UV-C no controle da microflora natural da alface MP foi influenciada, principalmente, pela dose aplicada. Não foram observadas diferenças entre tratamentos na contagem microbiológica de alface Americana MP, ao se avaliarem doses baixas referentes a tempos de exposição de até 2 min de exposição $\left(1,2\right.$ a $\left.3,6 \mathrm{~kJ} / \mathrm{m}^{2}\right)$, em relação à alface não tratada (Bachelli, 2016). Com o aumento da dose $\left(2,37\right.$ a $\left.8,14 \mathrm{~kJ} / \mathrm{m}^{2}\right)$, houve reduções entre 1 e 2 ciclos logarítmicos (log UFC/g) no crescimento de bactérias psicrotróficas, mesófilas, enterobactérias, coliformes e leveduras em alface MP Lollo Rosso e Red Oak Leaf, com as reduções mais significativas para as maiores doses empregadas. As contagens permaneceram 
inferiores às da alface não tratada durante praticamente todos os dias sob refrigeração e AM (Allende \& Artés, 2003a; Allende et al., 2006).

O emprego de radiação UV-C nas doses de 1,18 a $8,14 \mathrm{~kJ} / \mathrm{m}^{2}$ aumentou a vida útil da alface MP entre um e três dias, baseado no limite de $7 \log$ UFC/g para MAT (Allende \& Artés, 2003a), e de três dias, considerando o limite máximo para leveduras de $5 \log$ UFC/g (Allende et al., 2006). Entretanto, ao final do período de armazenamento (entre 7 e 10 dias), foram observadas, nesses estudos, contagens similares de bactérias psicrotróficas, coliformes e leveduras em ambas as alfaces, tratada e não tratada. Este fato indica que a radiação UV-C é capaz de manter as contagens microbiológicas da alface MP em níveis aceitáveis por um determinado período. Ainda, um aumento de $3 \log \mathrm{UFC} / \mathrm{g}$ na contagem de bactérias acidoláticas foi observada apenas no tratamento com a dose mais alta $\left(8,14 \mathrm{kJm}^{2}\right)$, enquanto que, para doses menores, as contagens para esse grupo se mantiveram inferiores (Allende \& Artés, 2003a). Este fato foi associado com a redução da microflora competitiva, maior resistência das bactérias Gram-positivas e disponibilidade de nutrientes, uma vez que, nessa dosagem, houve danos às folhas.

Uma vez que a eliminação da microflora natural pode favorecer o crescimento de patógenos (Fan et al., 2017), o efeito germicida da radiação UV-C tem sido observado tanto para o controle de microrganismos naturalmente presentes nos vegetais quanto para aqueles inoculados intencionalmente (Civello et al., 2006). Nesses estudos, as espécies introduzidas são geralmente patogênicas e inoculadas em altas concentrações ( 7 a $9 \log$ UFC/g), o que, por sua vez, demandou doses maiores para atingir uma inativação significativa. Birmpa et al. (2013), ao inocularem Salmonella enteritidis, E. coli, S. aureus e L. innocua na alface Romana MP, somente obtiveram reduções significativas a partir de uma dose de $24 \mathrm{~kJ} / \mathrm{m}^{2}$ após 20 min de exposição, atingindo reduções mais expressivas de 1 a $1,7 \log$ UFC/g com a dose de $54 \mathrm{~kJ} / \mathrm{m}^{2}$ após $45 \mathrm{~min}$ de exposição.

Kim et al. (2013) destacaram que os estudos envolvendo a radiação UV-C não levam em conta o efeito da temperatura do processo e outras variáveis que também influenciam a inativação dos microrganismos. De acordo com Fan et al. (2017), baixas temperaturas podem reduzir a potência emitida pela lâmpada, o que afetaria a intensidade da irradiação. Já a forma de exposição à radiação influencia na inativação microbiana, uma vez que as células precisam ser diretamente expostas à luz UV-C para serem inativadas. Por outro lado, quando a distância entre a fonte de radiação e o produto é reduzida, aumentam a intensidade de luz UV recebida e a interação com os microrganismos, permitindo maior inativação (Bermúdez-Aguirre \& Barbosa-Cánovas, 2013). Os valores para estes parâmetros operacionais utilizados nos estudos abordados são elencados na Tabela 2. Enquanto que, em alguns estudos, os valores foram fixados, em outros, os mesmos foram variados, permitindo comparação entre os resultados obtidos.

Tabela 2. Dados da literatura reportando a irradiação de alface minimamente processada com UV-C.

\begin{tabular}{ccccccc}
\hline Referência & $\begin{array}{c}\text { Forma de } \\
\text { exposição }\end{array}$ & $\begin{array}{c}\text { Temperatura } \\
\left({ }^{\circ} \mathbf{C}\right)\end{array}$ & $\begin{array}{c}\text { Distância } \\
(\mathbf{c m})\end{array}$ & $\begin{array}{c}\text { Intensidade UV } \\
\left(\mathbf{W} / \mathbf{m}^{2}\right)\end{array}$ & $\begin{array}{c}\text { Tempo } \\
(\mathbf{m i n})\end{array}$ & $\begin{array}{c}\text { Doses } \\
\left(\mathbf{k J} / \mathbf{m}^{2}\right)\end{array}$ \\
\hline $\begin{array}{c}\text { Allende \& Artés } \\
(2003 a, 2003 \mathrm{~b})\end{array}$ & Um lado & - & 60 & - & - & $0,41-8,41$ \\
\hline $\begin{array}{c}\text { Allende et al. } \\
(2006)\end{array}$ & Dois lados & 5 e 10 & 15 & - & - & $1,18-11,8$ \\
\hline Bachelli (2016) & Dois lados & - & 27 & 34,3 & $0,68-1,75$ & $1,2-3,6$ \\
\hline $\begin{array}{c}\text { Bermúdez-Aguirre } \\
\text { \& Barbosa- } \\
\text { Cánovas (2013) }\end{array}$ & - & $24-25$ & 31 e 70 & 6,5 e 16 & $0-60$ & $0-57,6$ \\
\hline $\begin{array}{c}\text { Birmpa et al. } \\
(2013)\end{array}$ & - & 25 & 8 & 20 & $10-60$ & $12-72$ \\
\hline Kim et al. (2013) & Dois lados & 4 e 25 & 10 e 50 & $13,6-68$ & $0,5-10$ & $0,41-40,8$ \\
\hline
\end{tabular}

Kim et al. (2013) variaram inicialmente os parâmetros temperatura, distância, forma de exposição e intensidade de radiação individualmente, obtendo redução da contagem dos patógenos inoculados E. coli O1:H57, $S$. Tiphymurium e L. monocytogenes na alface MP irradiada ampliada em, aproximadamente, $1 \mathrm{log} \mathrm{UFC} / \mathrm{g}$. 
Quando essas condições foram analisadas conjuntamente, observou-se uma substancial redução de mais de $4 \log$ UFC/g na microbiota intencional da alface MP (Kim et al., 2013). Nessa condição, dita otimizada, a temperatura aumentou de 4 para $25^{\circ} \mathrm{C}$, a distância diminuiu de 50 para $10 \mathrm{~cm}$, os dois lados do vegetal foram expostos às maiores intensidades $\left(68 \mathrm{~W} / \mathrm{m}^{2}\right)$ e dose de radiação (a partir de $20,4 \mathrm{~kJ} / \mathrm{m}^{2}$ ). Já Birmpa et al. (2013) irradiaram a alface Romana MP a $25^{\circ} \mathrm{C}$ e $8 \mathrm{~cm}$ distante das lâmpadas, porém obtiveram reduções inferiores de patógenos do mesmo gênero avaliados por Kim et al. (2013). No entanto, nesse estudo não foi informado se houve exposição em ambos os lados da alface.

Bermúdez-Aguirre \& Barbosa-Cánovas (2013) variaram a distância entre a lâmpada UV e a alface MP, como forma de aumentar a intensidade, obtendo redução de $1,7 \log \mathrm{UFC} / \mathrm{g}$ de E. coli quando a distância diminuiu de $70\left(6,5 \mathrm{~W} / \mathrm{m}^{2}\right)$ para $31 \mathrm{~cm}\left(16 \mathrm{~W} / \mathrm{m}^{2}\right)$, com a aplicação da maior dose de $57,6 \mathrm{~kJ} / \mathrm{m}^{2}$, por $60 \mathrm{~min}$ de exposição. Yaun et al (2004), por sua vez, avaliaram diferentes intensidades de radiação. Uma redução de Salmonella e E. coli de $2 \log$ UFC/g em alface cortada $\left(60 \mathrm{~W} / \mathrm{m}^{2}\right)$ foi aumentada quando a intensidade de radiação aumentou para $240 \mathrm{~W} / \mathrm{m}^{2}$, levando a reduções de 2,65 e 2,69 $\log \mathrm{UFC} / \mathrm{g}$, respectivamente. Uma redução de, aproximadamente, $1 \mathrm{log}$ UFC/g de bactérias acidoláticas da alface Red Oak Leaf foi atingida utilizando doses menores de 1,18 a $7,11 \mathrm{~kJ} / \mathrm{m}^{2}$, porém irradiando ambos os lados das folhas (Allende et al., 2006). O uso de bancos de lâmpadas UV em cima e embaixo da amostra é recomendado, pois o efeito da exposição mais completa da superfície à luz UV-C potencializa a inativação de microrganismos mais resistentes e requer o uso de menores doses.

Assegurar a exposição uniforme de uma superfície irregular como a da alface é uma limitação da técnica, assim como tem sido demonstrado para outros vegetais MP. Houve maior redução bacteriana de E. coli e Salmonella em maçã inteira (Yaun et al., 2004) e de E. coli no tomate inteiro (Bermúdez-Aguirre \& Barbosa-Cánovas, 2013), tratados com radiação UV-C, do que na alface MP, o que foi associado com características superficiais desses frutos. Já Birmpa et al. (2013) obtiveram maiores reduções de E. coli, S. enteriditis, S. aureus e L. innocua em alface MP do que em morango, associado à porosidade superficial da fruta. Em outro estudo, Syamaladevi et al. (2013) observaram que a inativação de E. coli com radiação UV-C foi afetada pela presença dos pelos da casca do pêssego e por injúrias na superfície da pera, comparado com a superfície intacta, indicando o efeito protetivo que estas irregularidades promovem aos microrganismos frente ao UV-C. Todavia, considerando a superfície de frutas e hortaliças MP como uma superfície injuriada devido ao corte, é primordial a otimização dos parâmetros supracitados como forma de melhorar a eficiência do UV-C.

\subsection{Cor e avaliação sensorial}

A proliferação microbiana em alimentos é caracterizada pela produção de enzimas e de metabólitos que induzem a alterações na aparência, na textura e no aroma (Ragaert et al., 2011). Na avaliação sensorial da alface MP, as maiores médias foram atribuídas a tratamentos referentes a doses de 4,07 a $8,14 \mathrm{~kJ} / \mathrm{m}^{2}$, para atributos de aparência global e cor, com destaque para o brilho das folhas (Allende \& Artés, 2003a). Doses baixas (até $2,40 \mathrm{~kJ} / \mathrm{m}^{2}$ ) tiveram as menores médias, sendo iguais às do controle, com alteração significativa da cor e menor intenção de compra (Allende \& Artés, 2003a; Bachelli, 2016). Escurecimento e amolecimento das folhas foram observados com o emprego de $7,11 \mathrm{~kJ} / \mathrm{m}^{2}$ e, aos sete dias de armazenamento, sendo estes os fatores que limitaram a aceitabilidade da alface MP tratada nessa dosagem (Allende et al., 2006).

A cor dos vegetais MP é certamente o fator decisivo no ato da compra e alterações na coloração dos vegetais verdes folhosos não são atrativas aos olhos do consumidor (Artés et al., 2007). Na alface, há um complexo sistema de compostos que alteram a sua coloração, tais como clorofila, carotenoides e enzimas peroxidase e polifenoloxidase (Bermúdez-Aguirre \& Barbosa-Cánovas, 2013). O uso de UV-C promoveu a preservação da cor das folhas por mais tempo, se sobressaindo em relação a outros métodos, como o ultrassom (Birmpa et al., 2013), o ozônio (Bermúdez-Aguirre \& Barbosa-Cánovas, 2013) e a água ozonizada (Bachelli, 2016), os quais, por sua vez, degradaram os compostos que dão cor às folhas. Porém, o emprego 
de doses altas (de $40,8 \mathrm{~kJ} / \mathrm{m}^{2}$ até $72 \mathrm{~kJ} / \mathrm{m}^{2}$ ) alteraram significativamente a cor da alface logo após o tratamento ou durante o armazenamento (Bermúdez-Aguirre \& Barbosa-Cánovas, 2013; Birmpa et al., 2013; Kim et al., 2013).

Os estudos disponíveis na literatura apontam que a radiação UV-C é capaz de reduzir o crescimento de microrganismos deteriorantes e patogênicos na alface MP logo após os tratamentos, aumentar a vida útil, comparado à hortaliça não tratada, mantendo os parâmetros de qualidade sensorial durante a maior parte do armazenamento. No entanto, a superfície irregular de suas folhas é levantada por muitos pesquisadores como um limitante da técnica e, além da dose, uma abordagem conjunta dos parâmetros envolvidos pode resultar em um efeito germicida mais amplo, considerando microrganismos patogênicos.

A otimização do processo pode superar, de certa forma, a limitação superficial de tratar a alface MP com radiação UV-C. Entretanto, não foi possível assegurar uma dosagem que seja eficaz na inativação da microflora, sem causar danos adicionais, uma vez que os estudos revisados abordaram diferentes cenários e condições experimentais que não permitem a comparação entre as doses (Tabela 2). Por exemplo, uma dose menor de $7,11 \mathrm{~kJ} / \mathrm{m}^{2}$ foi capaz de causar alteração indesejável na cor das folhas de alface Red Oak Leaf (Allende et al., 2006), porém uma alta dose de $28,8 \mathrm{~kJ} / \mathrm{m}^{2}$ alterou levemente a cor de alface Romana MP (Bermúdez-Aguirre \& Barbosa-Cánovas, 2013). Há um consenso entre os pesquisadores em utilizar as menores doses e/ou tempo de exposição possíveis a fim de reduzir a contaminação da alface MP sem alterar suas características de qualidade.

\section{Efeitos da radiação UV-C em maçã minimamente processada}

\subsection{Aspectos microbiológicos}

O uso de radiação UV-C também foi eficaz na sanitização de maçã MP, para doses de 1,2 a 14,1 kJ/m² e tempos de exposição entre 1 e 25 min. Houve reduções significativas de 1 a $2 \log$ UFC/g na contagem de MAT, enterobactérias, bolores e leveduras. Apesar de ter ocorrido crescimento de MAT, as contagens desses microrganismos no produto tratado mantiveram-se sempre inferiores em relação à maçã MP não tratada, abaixo do limite de $7 \mathrm{log}$ UFC/g durante todo o armazenamento ( 7 a 15 dias), indicando estabilidade microbiológica (Gómez et al., 2010, 2015; Chen et al., 2016). A contagem de MAT na maçã MP, inclusive, foi reduzida até mesmo para níveis abaixo do limite de deteç̧ão com um tratamento de $24 \mathrm{~kJ} / \mathrm{m}^{2}$ por 20 min (Manzocco et al., 2011b). Um aumento de oito dias na vida útil da maçã Fuji MP foi atingido para os cubos expostos à radiação UV-C por $5 \mathrm{~min}$ (Chen et al., 2016).

$\mathrm{O}$ aumento da intensidade de radiação e do tempo de exposição à luz UV-C em alimentos não leva, necessariamente, a um maior efeito germicida (Fan et al., 2017), sendo que a dose efetivamente absorvida pelo microrganismo é a responsável pela redução dos níveis de contaminação. Dessa forma, Manzocco et al. (2011b) sugeriram que tratamentos mais brandos podem ser aplicados e surtir os mesmos efeitos de tratamentos com doses mais severas. A radiação UV-C foi capaz de penetrar uma espessura de apenas $0,2 \mathrm{~mm}$ nos cubos da maçã, estando o efeito germicida limitado a essa espessura (Manzocco et al., 2011b). Esse efeito pode explicar por que o uso de menores doses ou tempos mais curtos de exposição causaram o mesmo efeito germicida que doses mais altas. Para fins de comparação, na Tabela 3, são mostrados os valores dos parâmetros do processo de irradiação com UV-C utilizados para a maçã MP. 
Tabela 3. Dados da literatura para parâmetros da exposição de maçã minimamente processada à radiação UV-C.

\begin{tabular}{clccccc}
\hline Referência & $\begin{array}{c}\text { Forma de } \\
\text { exposição }\end{array}$ & $\begin{array}{c}\text { Temperatura } \\
\left({ }^{\circ} \mathbf{C}\right)\end{array}$ & $\begin{array}{c}\text { Distância } \\
(\mathbf{c m})\end{array}$ & $\begin{array}{c}\text { Intensidade UV } \\
\left(\mathbf{W} / \mathbf{m}^{2}\right)\end{array}$ & $\begin{array}{c}\text { Tempo } \\
(\mathbf{m i n})\end{array}$ & $\begin{array}{c}\text { Doses } \\
\left(\mathbf{k J} / \mathbf{m}^{2}\right)\end{array}$ \\
\hline Chen et al. (2016) & Dois lados & - & - & - & 5 & - \\
\hline Chen et al. (2017) & Dois lados & 21 & 20 & 16 & $0,5-10$ & $0,48-9,6$ \\
\hline $\begin{array}{c}\text { Gómez et al. } \\
(2010,2011)\end{array}$ & Um lado & 27 & 10 & 9,3 & $0-20$ & $1,12-14,1$ \\
\hline $\begin{array}{c}\text { Gómez et al. } \\
(2015)\end{array}$ & Dois lados & 27 & 10 & - & 20 & 11,2 \\
\hline Graça et al. (2013) & Dois lados & - & 15 & - & - & $0,5-1,0$ \\
\hline $\begin{array}{c}\text { Manzocco et al. } \\
(2009 a, 2009 b)\end{array}$ & Dois lados & 4 & 13,8 & 13,8 & 5 & 4,14 \\
\hline $\begin{array}{c}\text { Manzocco et al. } \\
(2011 b)\end{array}$ & Dois lados & 6 & - & 20 & $1-20$ & $1,2-24$ \\
\hline Santo et al. (2016) & Dois lados & - & 15 & - & - & $2,5-10$ \\
\hline
\end{tabular}

A radiação UV-C promoveu uma redução significativa entre 1,0 e 2,2 log UFC/g na carga de microrganismos inoculados antes dos tratamentos, tais como Saccharomyces cerevisiae, L. innocua, E. coli, S. enterica e Cronobacter sakazakii, com doses entre 0,5 e $11,16 \mathrm{~kJ} / \mathrm{m}^{2}$ por até $20 \mathrm{~min}$. Nesses casos, o efeito germicida foi mais pronunciado com o uso de maiores doses (Gómez et al., 2010; Graça et al., 2013; Santo et al., 2016). Graça et al. (2013) obtiveram uma maior redução com doses baixas $\left(0,5\right.$ e $\left.1,0 \mathrm{~kJ} / \mathrm{m}^{2}\right) \mathrm{de}$ 1,4 a 4,1 $\log$ UFC/g quando um coquetel de patógenos (E. coli, S. enterica e L. innocua) foi inoculado, comparado aos resultados para os patógenos inoculados individualmente, o que foi associado à competição entre espécies pelos nutrientes. Chen et al. (2017) não observaram diferenças significativas na redução de $S$. enteriditis em maçã Fuji MP em função do aumento da dose além de $0,96 \mathrm{~kJ} / \mathrm{m}^{2}$ (1 min de exposição). Cabe destacar que, nesses estudos, em que a dose mínima significativa na inativação dos microrganismos foi baixa (em torno de $1 \mathrm{~kJ} / \mathrm{m}^{2}$ ), os dois lados dos cubos foram irradiados (Tabela 3 ).

\subsection{Cor e atividade enzimática}

Os efeitos observados na cor da maçã MP tratada com radiação UV-C foram dependentes da dose e do tempo de exposição. A cor da maçã MP não foi influenciada pelo uso de doses de UV-C até $1,0 \mathrm{~kJ} / \mathrm{m}^{2}$ para a variedade Golden Delicious (Graça et al., 2013) e, para tempos de exposição inferiores a 10 min, doses de 1,2 a $12 \mathrm{~kJ} / \mathrm{m}^{2}$ em maçã Red Pink Lady (Manzocco et al., 2011b), 5,6 kJ/m² em maçã Granny Smith (Gómez et al., 2010) e 9,6 kJ/m² para maçã Fuji (Chen et al., 2017). Já o aumento do tempo de exposição à radiação UV-C a partir de 15 min causou um pronunciado escurecimento, em maior grau do que a maçã não tratada com UV-C, com doses entre $8,4 \mathrm{~kJ} / \mathrm{m}^{2}$ e $24 \mathrm{~kJ} / \mathrm{m}^{2}$ (Gómez et al., 2010; Manzocco et al., 2011b).

Uma inibição do escurecimento da maçã MP tratada foi obtida com a imersão em soluções de antioxidantes prévia ao tratamento com a luz UV-C, sendo eficaz independentemente da dose aplicada (Gómez et al., 2010, 2015; Chen et al., 2016). Esses pré-tratamentos atuam alterando os substratos para o escurecimento e foram necessários tendo em vista que a maçã MP adquiriu coloração inaceitável em decorrência do aumento da dose (Gómez et al., 2010, 2015), possibilitando o uso de doses mais altas de radiação UV-C na maçã MP.

O escurecimento enzimático de vegetais MP é um processo químico natural que ocorre quando a célula perde a sua compartimentalização funcional devido ao corte, expondo as enzimas aos seus substratos (Gómez et al., 2010). A maçã é reconhecida por sua propensão ao escurecimento após o corte, devido à atividade de enzimas oxidativas, como a polifenoloxidase (PPO). Alguns estudos buscaram explicar esse efeito de preservação da cor investigando uma provável inativação da PPO em decorrência da exposição da maçã MP aos raios UV-C. No entanto, devido à baixa absorbância da luz UV-C no tecido da maçã, uma exposição de 5 min ocasionou apenas uma inativação superficial da enzima, retardando o escurecimento da 
superfície ao longo do armazenamento. Não houve diferença significativa entre a atividade da PPO na maçã irradiada comparada à da amostra não tratada (Manzocco et al., 2009a; Chen et al., 2016).

Por outro lado, o escurecimento de tecidos irradiados com UV, verificado para doses mais altas, tem sido associado com o contato entre enzimas e substratos devido ao rompimento das células (Manzocco et al., 2011b). Porém, Manzocco et al. (2009a) observaram que o escurecimento do suco de maçã e de uma solução aquosa de catequina, composto fenólico presente na maçã, ocorreu após a exposição à luz UV-C independentemente da atividade da PPO, por meio da foto-oxidação direta dos compostos fenólicos. A possível formação de uma fina camada seca na superfície das frutas, em decorrência da irradiação com luz UV-C (Manzocco et al., 2011a, 2011b), atuaria como barreira ao oxigênio necessário para as reações enzimáticas (Chen et al., 2016). Portanto, esse efeito inibitório do escurecimento em decorrência do emprego de luz UV-C estaria relacionado ao uso de baixas doses, incapazes de causar danos severos aos tecidos.

\subsection{Danos estruturais, firmeza e perda de massa}

Alterações na cor da maçã MP irradiada com maiores doses de radiação UV-C foram relacionadas à indução de mudanças estruturais (Gómez et al., 2015). Compostos fotoativos podem absorver energia no comprimento de onda da radiação UV-C e doses altas podem levar ao rompimento das membranas, favorecendo a oxidação enzimática dos compostos fenólicos (Civello et al., 2006). Em seus trabalhos, Gómez et al. (2010, 2011, 2015) demonstraram, por meio de micrografias do parênquima da superfície irradiada de maçã Granny Smith MP, que a dose de $11,2 \mathrm{~kJ} / \mathrm{m}^{2}$ de radiação UV-C provocou uma desorganização da estrutura celular, com rompimento de membranas, extravasamento do conteúdo citoplasmático, perda da turgidez, inchaço e arredondamento das células, além de um rearranjo dos espaços intercelulares. Deformações, como o encolhimento e dobramento das paredes celulares, foram observadas no armazenamento subsequente, cujo dano está diretamente relacionado com a dose de radiação UV-C. Embora a radiação UV-C tenha causado ruptura celular, não foi observada, nesses estudos, influência sobre as propriedades viscoelásticas e reológicas da maçã MP, estando os danos mais associados com defeitos visuais e a desidratação.

Vários estudos corroboram com a hipótese de que a radiação UV-C não afeta a textura dos produtos ao longo do armazenamento, expressa pela firmeza. Para a maçã MP tratada com doses de 0,48 a $24 \mathrm{~kJ} / \mathrm{m}^{2}$, a firmeza não diferiu significativamente em relação ao controle (Manzocco et al., 2011b; Chen et al., 2016, 2017). Controversamente, a variedade Golden Delicious MP tratada com $4,14 \mathrm{~kJ} / \mathrm{m}^{2}$ foi mais firme que o controle, sendo que, nesta condição, houve maior perda de massa (Manzocco et al., 2009b).

A perda de massa, associada com a perda de água pelo produto (Gómez et al., 2011), aumenta substancialmente durante o armazenamento devido à exposição da polpa a um ambiente de menor umidade relativa (Chen et al., 2016), sendo este um importante parâmetro para mensurar o dano causado pela luz UV-C. Assim como para a cor, houve maior perda de massa na maçã MP tratada com o aumento da dose aplicada. A dose de $4,14 \mathrm{~kJ} / \mathrm{m}^{2}$ promoveu uma significativa perda de massa na maçã MP, sendo considerado um dano adicional ao causado pelo processamento mínimo (Manzocco et al., 2009b; Gómez et al., 2011). A fim de verificar os efeitos da exposição prolongada à radiação UV-C $\left(144 \mathrm{~kJ} / \mathrm{m}^{2}\right)$, Manzocco et al. (2011b) observaram uma pronunciada desidratação do tecido irradiado em decorrência da ruptura da membrana celular. Pode-se afirmar que há uma correlação entre o aumento da perda de massa da maçã MP e o aumento da exposição à radiação UV-C devido à perda do conteúdo celular, além da observada, devido ao corte.

\subsection{Avaliação sensorial}

Avaliações sensoriais dos produtos MP tratados com radiação UV-C constituem uma importante ferramenta para determinar a sua qualidade. O escurecimento de vegetais MP é um dos problemas que mais afetam a comercialização dos mesmos (Chen et al., 2016), uma vez que a cor e a aparência são os atributos 
mais julgados pelo consumidor na escolha de um produto (Artés et al., 2007a). O tratamento com radiação UV-C em baixas doses (1,2 a 4,14 kJ/m²) não afetou a aparência (Manzocco et al., 2009a), a percepção de firmeza e o aroma da maçã MP, em comparação aos controles (sem tratamento) durante o armazenamento (Manzocco et al., 2011b). Correlacionando o perfil de textura instrumental com o sensorial (dureza, fraturabilidade, crocância e suculência), Gómez et al. (2011) verificaram que os painelistas apenas perceberam diferenças significativas entre a maçã Granny Smith MP tratada $\left(11,2 \mathrm{~kJ} / \mathrm{m}^{2}\right)$ e não tratada, para os parâmetros de fraturabilidade e suculência.

A maçã MP apresentou uma alta susceptibilidade a alterações, como o escurecimento e a perda de massa, em decorrência do dano celular causado pelo aumento da dose de radiação UV-C, observadas principalmente em frutos expostos por mais de 10 min. Devido à baixa penetração, os danos causados pela radiação UV-C em doses moderadas se limitam à superfície da maçã MP, porém são suficientes para causar alterações significativas em parâmetros sensoriais, como a cor, firmeza e suculência. Doses mais altas de radiação UV-C puderam ser aplicadas em maçã MP, desde que com a imersão prévia em antioxidantes, sem comprometer a sua aparência. No entanto, há evidências científicas que mostram que tratamentos severos podem ser substituídos por doses mais brandas, mantendo o mesmo efeito germicida e prevenindo tais danos aos frutos. Como, em alguns casos, diferentes resultados foram observados levando em conta a relação entre a dose utilizada e a variedade de maçã, mais estudos a respeito da variedade dos frutos e a sensibilidade em relação ao UV-C se fazem necessários a fim de fornecer dados mais concretos.

\section{Conclusão}

Os efeitos da aplicação de radiação UV-C sobre dois tipos diferentes de vegetais minimamente processados, alface e maçã, foram revisados. A carga microbiana natural destes vegetais pode ser facilmente reduzida em torno de 1 a $2 \log$ UFC/g logo após os tratamentos, o que leva a um satisfatório aumento da vida de prateleira dos produtos. Foi verificada que, para a alface MP, uma redução significativa de mais de $4 \mathrm{log} \mathrm{UFC} / \mathrm{g}$ de microrganismos patogênicos pode ser alcançada considerando parâmetros do processo, como forma de aumentar a exposição de superfície irregular. Para a maçã MP, o controle do tempo de exposição à radiação UV-C foi importante para controlar o escurecimento superficial e a perda de massa. O ajuste de parâmetros do processo de irradiação pode ser útil para otimizar o uso desta técnica. Há necessidade de mais estudos que possam sugerir formas de aplicar industrialmente este método superficial de sanitização de baixos custo e impacto ambiental em vegetais MP sem comprometer a sua qualidade.

\section{Referências}

Allende, A., \& Artés, F. (2003a). UV-C radiation as a novel technique for keeping quality of fresh processed 'Lollo Rosso' lettuce. Food Research International, 36(7), 739-746. http://dx.doi.org/10.1016/S0963-9969(03)00054-1

Allende, A., \& Artés, F. (2003b). Combined ultraviolet-C and modified atmosphere packaging treatments for reducing microbial growth of fresh processed lettuce. Lebensmittel-Wissenschaft + Technologie, 36(8), 779-786. http://dx.doi.org/10.1016/S00236438(03)00100-2

Allende, A., Mcevoy, J. L., Luo, Y., Artés, F., \& Wang, C. Y. (2006). Effectiveness of two-sided UV-C treatments in inhibiting natural microflora and extending the shelf-life of minimally processed 'Red Oak Leaf' lettuce. Food Microbiology, 23(3), $241-249$. PMid:16943010. http://dx.doi.org/10.1016/j.fm.2005.04.009

Alothman, M., Bhat, R., \& Karim, A. A. (2009). Effects of radiation processing on phytochemicals and antioxidants in plant produce. Trends in Food Science \& Technology, 20(5), 201-212. http://dx.doi.org/10.1016/j.tifs.2009.02.003

Artés, F., Gómez, P. A., \& Artés-Hernández, F. (2007a). Physical, physiological and microbial deterioration of minimally fresh processed fruits and vegetables. Food Science \& Technology International, 13(3), 177-188. http://dx.doi.org/10.1177/1082013207079610

Artés, F., Gómez, P. A., Artés-Hernández, F., Aguayo, E., \& Escalona, V. (2007). Improved strategies for keeping overall quality of fresh-cut produce. In S. Kanlayanarat, P. M. A. Toivnonen \& K. C. Gross (Eds.), International Conference on Quality Management of Fresh-Cut Produce (Vol. 1, pp. 245-258). Bangkok: Acta Horticulturae. http://dx.doi.org/10.17660/ActaHortic.2007.746.27 
Bachelli, M. L. B. (2016). Avaliação da radiação ultravioleta C e água ozonizada para sanitização de alface e mamão minimamente processados (Tese de doutorado). Faculdade de Engenharia Agrícola, Universidade Estadual de Campinas, Campinas.

Bermúdez-Aguirre, D., \& Barbosa-Cánovas, G. V. (2013). Disinfection of selected vegetables under nonthermal treatments: Chlorine, acid citric, ultraviolet light and ozone. Food Control, 29(1), 82-90. http://dx.doi.org/10.1016/j.foodcont.2012.05.073

Birmpa, A., Sfika, V., \& Vantarakis, A. (2013). Ultraviolet light and ultrasound as non-thermal treatments for the inactivation of microorganisms in fresh ready-to-eat foods. International Journal of Food Microbiology, 167(1), 96-102. PMid:23827815. http://dx.doi.org/10.1016/j.ijfoodmicro.2013.06.005

Cantwell, M., \& Suslow, T. (2002). Fresh-cut fruits and vegetables: Aspects of phisiology, preparation and handling that affect quality. In A. Kader (Ed.), Postharvest technology of horticultural crops (3rd ed.,535 p.). Oakland: Division of Agriculture and Natural Resources,University of California.

Chen, A., Luo, W., Luo, Y., \& Zhu, B. (2017). Combined treatment of ultraviolet-C and L. plantarum on Salmonella enteritidis and quality control of fresh-cut apple. Journal of Food Processing and Preservation, 41(1), e13349. http://dx.doi.org/10.1111/jpp.13349

Chen, C., Hu, W., He, Y., Jiang, A., \& Zhang, R. (2016). Effect of citric acid combined with UV-C on the quality of fresh-cut apples. Postharvest Biology and Technology, 111, 126-131. http://dx.doi.org/10.1016/j.postharvbio.2015.08.005

Cisneros-Zevallos, L. (2003). The use of controlled postharvest abiotic stresses as a tool for enhancing the nutraceutical content and adding-value of fresh fruits and vegetables. Journal of Food Science, 68(5), 1560-1565. http://dx.doi.org/10.1111/j.13652621.2003.tb12291.x

Civello, P. M., Vicente, A. R., \& Martínez, G. A. (2006). UV-C technology to control postharvest diseases of fruits and vegetables. In R. Troncoso-Rojas, M. E. Tiznado-Hernández \& A. González-León (Eds.), Recent advances in alternative postharvest technologies to control fungal diseases in fruits \& vegetables (Chap. 4, pp. 71-102), Kerala, India: Research Signpost.

Cutler, T. D., \& Zimmerman, J. J. (2011). Ultraviolet irradiation and the mechanisms underlying its inactivation of infectious agents. Animal Health Research Reviews, 12(1), 15-23. PMid:21676338. http://dx.doi.org/10.1017/S1466252311000016

Fan, X., Huang, R., \& Chen, H. (2017). Application of ultraviolet C technology for surface decontamination of fresh produce. Trends in Food Science \& Technology, 70, 9-19. http://dx.doi.org/10.1016/j.tifs.2017.10.004

Gayán, E., Condón, S., \& Álvarez, I. (2014). Biological aspects in food preservation by ultraviolet light: A review. Food and Bioprocess Technology, 7(1), 1-20. http://dx.doi.org/10.1007/s11947-013-1168-7

Gómez, L. P., Alzamora, S. M., Castro, M. A., \& Salvatori, D. M. (2010). Effect of ultraviolet-C light dose on quality of cut-apple: Microorganism, color and compression behavior. Journal of Food Engineering, 98(1), 60-70.

http://dx.doi.org/10.1016/j.jfoodeng.2009.12.008

Gómez, P. L., García-Loredo, A., Salvatori, D. M., Guerrero, S., \& Alzamora, S. M. (2011). Viscoelasticity, texture and ultrastructure of cut apple as affected by sequential anti-browning and ultraviolet-C light treatments. Journal of Food Engineering, 107(2), 214-225. http://dx.doi.org/10.1016/j.jfoodeng.2011.05.046

Gómez, P. L., Schenk, M. L., Salvatori, D. M., \& Alzamora, S. M. (2015). Potential of UV-C light for preservation of cut apples fortified with calcium: Assessment of optical and rheological properties and native flora dynamics. Food and Bioprocess Technology, 8(9), 1890-1903. http://dx.doi.org/10.1007/s11947-015-1545-5

Graça, A., Salazar, M., Quintas, C., \& Nunes, C. (2013). Low dose UV-C illumination as an eco-innovative disinfection system on minimally processed apples. Postharvest Biology and Technology, 85, 1-7.

http://dx.doi.org/10.1016/j.postharvbio.2013.04.013

Kim, Y. H., Jeong, S. G., Back, K. H., Park, K. H., Chung, M. S., \& Kang, D. H. (2013). Effect of various conditions on inactivation of Escherichia coli O157:H7, Salmonella Typhimurium, and Listeria monocytogenes in fresh-cut lettuce using ultraviolet radiation. International Journal of Food Microbiology, 166(3), 349-355. PMid:24021819. http://dx.doi.org/10.1016/j.ijfoodmicro.2013.08.010

Koutchma, T., \& Orlowska, M. (2012). Ultraviolet light for processing fruits and fruit products. In S. Rodrigues \& F. A. N. Fernandes (Eds.), Advances in fruit processing technologies (Chap. 1, pp. 2-27). Boca Raton: CRC Press. http://dx.doi.org/10.1201/b12088-2

Maharaj, R. (2015). Effects of abiotic stress (UV-C) induced activation of phytochemicals on the postharvest quality of horticultural crops. In V. A. Rao \& L. G. Rao (Eds.), Phytochemicals: Isolation, characterization and role in human health (Chap. 9, pp. 221-244). London: InTechOpen.

Manzocco, L., Quarta, B., \& Dri, A. (2009a). Polyphenoloxidase inactivation by light exposure in model systems and apple derivatives. Innovative Food Science \& Emerging Technologies, 10(4), 506-511. http://dx.doi.org/10.1016/j.ifset.2009.02.004

Manzocco, L., Dri, A., \& Quarta, B. (2009b). Inactivation of pectic lyases by light exposure in model systems and fresh-cut apple. Innovative Food Science \& Emerging Technologies, 10(4), 500-505. http://dx.doi.org/10.1016/j.ifset.2009.06.002

Manzocco, L., Da Pieve, S., \& Maifreni, M. (2011a). Impact of UV-C light on safety and quality of fresh-cut melon. Innovative Food Science \& Emerging Technologies, 12(1), 13-17. http://dx.doi.org/10.1016/j.ifset.2010.11.006

Manzocco, L., Da Pieve, S., Bertolini, A., Bartolomeoli, I., Maifreni, M., Vianello, A., \& Nicoli, M. C. (2011b). Surface decontamination of fresh-cut apple by UV-C light exposure: Effects on structure, color and sensory properties. Postharvest Biology and Technology, 61(2-3), 165-171. http://dx.doi.org/10.1016/j.postharvbio.2011.03.003 
Montero-Calderón, M., \& Cerdas-Araya, M. M. (2011). Fruits and vegetables for the fresh-cut processing industry. In O. MartínBelloso \& R. Soliva-Fotuny (Eds.), Advances in fresh-cut fruits and vegetables processing (Chap. 7, pp. 185-209).Boca Raton: CRC Press.

Nguyen-the, C., \& Carlin, F. (1994). The microbiology of minimally processed fruits and vegetables. Critical Reviews in Food Science and Nutrition, 34(4), 371-401. PMid:7945895. http://dx.doi.org/10.1080/10408399409527668

Ragaert, P., Jacxsens, I. V., Baert, L., \& Devlieghere, F. (2011). Microbiological and safety aspects of fresh-cut fruits and vegetables. In O. Martín-Belloso \& R. Soliva-Fotuny (Eds.), Advances in fresh-cut fruits and vegetables processing (Chap. 3, pp. 53-86). Boca Raton: CRC Press.

Ribeiro, C., Canada, J., \& Alvarenga, B. (2012). Prospects of UV radiation for application in postharvest technology. Emirates Journal of Food and Agriculture, Abu Dhabi, 24(6), 586-597. http://dx.doi.org/10.9755/ejfa.v24i6.586597

Rojas-Graü, M. A., Garner, E., \& Martín-Belloso, O. (2011). The fresh-cut fruit and vegetables industry: Current situation and market trends. In O. Martín-Belloso \& R. Soliva-Fotuny (Eds.), Advances in fresh-cut fruits and vegetables processing (Chap. 1, pp. 1-11). Boca Raton: CRC Press.

Santo, D., Graça, A., Nunes, C., \& Quintas, C. (2016). Survival and growth of Cronobacter sakazakii on fresh-cut fruit and the effect of UV-C illumination and electrolyzed water in ther reduction of its population. International Journal of Food Microbiology, 231, 10-15. PMid:27163653. http://dx.doi.org/10.1016/j.ijfoodmicro.2016.04.023

Sethi, S., Joshi, A., \& Arora, B. (2018). UV treatment of fresh fruits and vegetables. In M. W. Siddiqui (Ed.), Postharvest disinfection of fruits and vegetables (Chap. 7, pp. 137-157). Cambridge: Academic Press. http://dx.doi.org/10.1016/B978-0-12812698-1.00007-8.

Syamaladevi, R. M., Lu, X., Sablani, S. S., Insan, S. K., Adhikari, A., Killinger, K., Rasco, B., Dhingra, A., Bandyopadhyay, A., \& Annapure, U. (2013). Inactivation of Escherichia coli population on fruit surfaces using ultraviolet-C light: Influence of fruit surface characteristics. Food and Bioprocess Biotechnology, 6(11), 2959-2973. http://dx.doi.org/10.1007/s11947-012-0989-0

Yaun, B. R., Sumner, S. S., Eifert, J. D., \& Marcy, J. E. (2004). Inhibition of pathogens on fresh produce by ultraviolet energy. International Journal of Food Microbiology, 90(1), 1-8. PMid:14672825. http://dx.doi.org/10.1016/S0168-1605(03)00158-2 